\title{
Casos de polissemia e escolhas de tradução do conto $O$ pequeno robot perdido, de Isaac Asimov
}

\section{Cases of polysemy and translation choices in Isaac Asimov's short story Little lost robot}

Fernanda Libério Pereira* Lenita Maria Rimoli Pisetta**

Resumo: neste trabalho analisaremos a tradução de termos polissêmicos do conto de Ficção Científica Little lost robot (1947), de Isaac Asimov, publicado no Brasil em 1958 sob o título $O$ pequeno robot perdido. Consideraremos a hipótese de que o autor utiliza a polissemia como ferramenta criativa e que os jogos polissêmicos adquirem importância no próprio enredo, devendo ser mantidos na tradução. A fim de contextualizar a análise, discutiremos a conceituação de polissemia e os desafios enfrentados em seu processo de tradução, além de comentar a relação das obras de Asimov com a investigação da competência comunicativa e do desenvolvimento cognitivo de humanos e robôs. Finalmente, abordaremos as possíveis motivações para as escolhas tradutórias empregadas na versão brasileira do conto, avaliando se o texto foi capaz de reproduzir a multiplicidade semântica explorada na obra original.

Palavras-chave: Polissemia; Tradução; Ficção Científica; Isaac Asimov.

Abstract: this work analyses the translation of polysemic terms in the Science Fiction short story Little lost robot (1947), by Isaac Asimov, published in Brazil in 1958 under

\footnotetext{
* Mestre pelo Programa de Pós-graduação em Estudos da Tradução da Universidade de São Paulo. E-mail: fernandaliberio@usp.br.

** Professora em níveis de graduação e pós-graduação do Departamento de Letras Modernas da Faculdade de Filosofia, Letras e Ciências Humanas da Universidade de São Paulo. E-mail: lenitaesteves@usp.br
} 
the title $O$ pequeno robot perdido. We will consider the hypothesis that the author uses polysemy as a creative tool and that polysemic games acquire importance in the plot, becoming imperative to the translation. To contextualize this analysis, we will discuss the conceptualization of polysemy and the challenges within its translation process. We will also comment on the relation of Asimov's works with the investigation of communicative competence and cognitive development in humans and robots. Finally, we will approach the possible motivations for the translation choices in the Brazilian version of the story and evaluate if the text is able to reproduce the semantic multiplicity explored in the original narrative.

Keywords: Polysemy, Translation; Science Fiction; Isaac Asimov.

\section{Introdução}

O conto Little lost robot, publicado em 1947 por Isaac Asimov, foi traduzido ao português e publicado no Brasil no ano de 1958 sob o título 0 pequeno robot perdido, como parte da coletânea As maravilhas da Ficção Científica, uma das primeiras do gênero organizadas no país.

A narrativa, que originalmente faz parte de uma série de contos de Asimov publicados individualmente entre os anos de 1940 e 1950, e posteriormente como a coletânea I, robot (1950), é construída em um panorama distópico onde a existência de robôs já é uma realidade de grande impacto na organização e desenvolvimento da sociedade humana. Tais robôs foram criados pelos homens para servir e obedecer, sendo configurados para serem submissos aos humanos sob quaisquer circunstâncias.

Para garantir a segurança e o controle sobre essas máquinas, são elaboradas pela comunidade científica algumas leis responsáveis por reger o comportamento dos robôs, com o intuito de prevenir e inibir condutas que possam representar riscos e desobediência. Seguindo esse propósito, Asimov introduz na história as três leis da robótica, diretrizes que serão utilizadas como premissa para todas as narrativas da série de contos. Por meio desse regimento, o autor se aproveita do espaço de interpretação disponibilizado pela construção semântica e lexical das leis como pano de fundo para uma série de acontecimentos relacionados ao comportamento dos robôs e à interpretação 
que tais máquinas são capazes de realizar das leis, além dos efeitos gerados por circunstâncias que as modifiquem.

Reconhecendo a tendência demonstrada por Asimov em explorar temas relacionados à competência comunicativa e capacidade cognitiva de humanos e robôs, consideramos a hipótese da utilização da polissemia como ferramenta criativa aplicada propositalmente pelo autor, permitindo a identificação de elementos onde a variedade semântica se mostra responsável por gerar relevantes consequências ao desenrolar da história. Partindo desse pressuposto, este trabalho analisa dois enunciados polissêmicos que desencadeiam acontecimentos importantes na narrativa, investigando também como eles foram traduzidos para o português do Brasil na primeira versão publicada do conto no país.

A polissemia, definida como um fenômeno no qual um mesmo item lexical pode carregar vários significados, tem tido grande papel na literatura como ferramenta criativa, sendo capaz de gerar situações problemáticas que enriquecem as narrativas e que podem demandar do leitor certo exercício de reflexão para acompanhar as histórias. No caso de Little lost robot, Isaac Asimov parece dar início à narrativa já tendo estabelecido o uso da multiplicidade de sentidos como justificativa para o desenvolvimento da ação central da obra, responsável por gerar todos os seus demais desdobramentos.

Um dos casos que apresenta a polissemia como possível ferramenta criativa no conto é representado pelo verbo modal may, utilizado na construção da primeira lei da robótica. O outro enunciado analisado é "Go lose yourself" (AsImov 2004: 82), ordem proferida por um dos cientistas ao robô que se perde, acontecimento que dá título à história. A quantidade de sentidos contida nesses elementos e suas aplicações ao contexto específico da narrativa construída por Asimov se revelam interessantes pontos de análise da obra, principalmente quando consideramos as discussões acerca da competência comunicativa e do conhecimento cognitivo.

Para identificar se o termo may e a frase go lose yourself permaneceram com seu caráter polissêmico no texto traduzido, justificando as ações que se desenvolveram na narrativa a partir de tais gatilhos, é necessário analisar se o tradutor considerou tais aspectos em sua leitura da obra original e por quais 
elementos optou ou conseguiu transportar a adaptação do texto à língua de chegada.

Dessa forma, com o objetivo de discutir e analisar os principais elementos polissêmicos do conto Little lost robot e as escolhas de tradução feitas na publicação brasileira de 1958, tendo como premissa a hipótese de utilização intencional da ambiguidade na obra como artifício criativo, este artigo realizará um resgate dos conceitos de polissemia e sua relação com a tradução, além de um mergulho mais aprofundado no universo distópico criado por Asimov e as relações entre o campo cognitivo do homem e da máquina.

\section{Polissemia e tradução}

A polissemia, fenômeno estrutural da linguagem pelo qual a uma só palavra são atribuídos vários significados, é um elemento frequentemente detectado em obras literárias dos mais diversos gêneros, sendo classificada muitas vezes como importante artifício criativo da literatura. A variedade de sentidos ligados apenas a um único item lexical oferece um maior número de caminhos a serem explorados na interpretação de um texto e mesmo a constante reflexão sobre a possível intenção do autor por um público instigado a mergulhar de forma mais profunda em sua leitura.

Diante desse fenômeno, as possíveis dificuldades de interpretação parecem ser desafios que podem ser superados por meio da análise etimológica, semântica, ou, principalmente, contextual. No entanto, como seriam solucionadas essas situações em um ambiente de transposição de conteúdo entre idiomas?

Assim como defendido por Stephen Ullmann (1964: 331) e outros autores, e como a consideramos aqui, a polissemia é um fenômeno natural e fundamental à linguagem e, por isso, inerente ao desenvolvimento da competência comunicativa do falante de qualquer idioma. Dessa forma, o processo de adaptação de um texto entre a língua de partida (LP) e a língua de chegada (LC) naturalmente encararia também as particularidades resultantes da combinação de itens lexicais com diferentes significados. 
A busca pela equivalência de termos ou expressões monossêmicas é uma prática comumente empregada no processo de tradução, no entanto, diante da noção da inviabilidade de seu alcance total - resultante das especificidades da língua, cultura, contexto histórico, carga semântica e etimológica, dentre outros aspectos - a prática tradutória muitas vezes estabelece como alternativa o emprego de correspondentes próximos, neologismos e, inclusive, empréstimos lexicais. Frente à necessidade de tradução de termos com múltiplos significados, a busca por um equivalente exato a um item polissêmico não seria, portanto, tarefa muito fácil.

A opção disponível aos tradutores que se deparam com essa situação seria, para Leona Van Vaerenbergh (2009: 57), obrigatoriamente, a constante análise das diferentes teorias de tradução para a construção de um arcabouço próprio de conceitos e postulações que os guiem na busca de correspondentes capazes de reproduzir o sentido (ou os vários sentidos) original(is) do item em questão.

Defendendo uma abordagem mais objetiva, Lederer (1976 apud DELABASTITA 1993: 167) alega que o contexto seria o principal encarregado de esclarecer possíveis dúvidas quanto à multiplicidade de sentidos de um item lexical. Dirk Delabastita (1993: 167) chega a alegar que em muitos casos a polissemia, ou a ambiguidade em um contexto maior, não chegará nem a ser identificada pelos tradutores, muito menos classificada como elemento problemático ou aspecto carente de atenção especial.

Essa perspectiva se mostra preocupante para muitos que consideram um cenário de utilização da polissemia como ferramenta criativa em obras literárias. Segundo Rosa Rabadán, por exemplo, quando a polissemia surge por desejo do autor e aparece repetidamente, ou possui importante papel na construção da narrativa, a tradução corre grandes riscos de se desfazer dessa essência original, impossibilitando a transferência adequada daquele texto à LC (RABADÁN 1991: 120).

Compreendendo os riscos envolvidos na tradução polissêmica, aplicada especificamente em uma narrativa de ficção, Kemp Malone (1979: 208) afirma que qualquer esforço do tradutor para encontrar um termo polissêmico totalmente correspondente será, na melhor das hipóteses, inútil. Para ele, tal 
tentativa teria, na verdade, maiores chances de trazer prejuízos à tradução, comprometendo-a total ou parcialmente.

Malone acaba, então, por resumir a problemática da tradução polissêmica à improbabilidade, na maioria dos casos, de conhecimento das intenções de um autor pelo tradutor de sua obra: "Tudo depende, em primeiro lugar, das intenções do autor fonte em utilizar a polissemia - e são exatamente essas intenções que quase nunca estão claras para o tradutor (MALONE 1979: 209) (Tradução nossa) ${ }^{1}$.

Considerando os posicionamentos apresentados acerca do tema, entendemos que a relação entre tradução e polissemia é representada por um cenário ainda de muitas incertezas, característica perceptível pelas visões acima citadas. Entretanto, considerando a análise do papel da polissemia no conto Little lost robot e nas escolhas realizadas em sua tradução para o português brasileiro na versão da obra publicada em 1958, decidimos por adotar a perspectiva da tradução polissêmica como processo relevante e responsável por possíveis consequências à transposição de um conteúdo literário.

\section{O universo asimoviano e a linguagem como temática literária}

O conto Little lost robot, do autor russo-americano Isaac Asimov, foi publicado pela primeira vez em 1947 como parte da coletânea Astounding Science Fiction, revista americana especializada em narrativas do gênero de Ficção Cientifica ( $\mathrm{FC}$ ). Inicialmente divulgada como história isolada, Little lost robot logo apareceu junto a outros oito contos escritos por Asimov que compunham a marcante coletânea $I$, robot (1950), série de textos que apresenta uma sociedade distópica marcada pela presença de robôs e suas formas de interação com o ser humano e o mundo ali criado.

\footnotetext{
${ }^{1}$ All rather depends on the source author's intentions in using the polysemy in the first place and it is just those intentions which remain unclear to the translator (MALONE 1979: 209).
}

TradTerm, São Paulo, v.35, junho/2020, p. 25-48

www. revistas.usp.br/tradterm 
A coletânea é composta por textos que seguem a mesma linha narrativa e que dialogam entre si, mas que podem ser lidos separadamente por sempre apresentarem novos elementos à discussão da relação entre o homem e a tecnologia e por fazerem referência a elementos chave à compreensão do universo criado pelo autor. Em busca de uma melhor compreensão da proposta criativa por trás da obra de Asimov, é interessante resgatar algumas de suas motivações e principais características como escritor.

\subsection{Asimov e a relação entre o homem e a tecnologia}

Considerado como um dos grandes autores da literatura de Ficção Científica ( $F C$ ), Isaac Asimov é conhecido pela criação de obras que abordam, sob diferentes perspectivas, o desenvolvimento científico-tecnológico e o peso de sua interferência, positiva ou negativa, na vida humana. Em coluna publicada pelo jornal The New York Times, em 1961, o autor confirma seu grande interesse em explorar a temática da relação entre o homem e a sociedade, ressaltando, ainda, que essa discussão seria uma das mais importantes funções da FC como gênero literário.

0 volume de obras escritas por Asimov é grande, envolvendo publicações de ficção e não-ficção que passam por diversas áreas do conhecimento; no entanto, o maior reconhecimento da carreira do autor se deve às narrativas distópicas de FC. Dentro dessa temática, o autor explora constantemente a busca humana pelo equilíbrio entre o desenvolvimento e o controle de tecnologias, e o medo de um crescimento tecnológico desordenado que pudesse produzir resultados catastróficos à raça humana.

É na tentativa de explorar a busca da confiança entre homem e máquina que Asimov desenvolve dentro de sua obra as leis da robótica, diretrizes responsáveis por garantir o comportamento exemplar dos robôs junto à sociedade:

(1) No robot may injure a human being, or, through inaction, allow a human being to come to harm.

(2) A robot must obey the orders given it by human beings except where such orders would conflict with the first law.

TradTerm, São Paulo, v.35, junho/2020, p. 25-48 www.revistas.usp.br/tradterm 
(3) A robot must protect its own existence as long as such protection does not conflict with the First or Second Law. (Asimov 2004).

Essas leis, que serão utilizadas em várias obras asimovianas, são apresentadas como uma tentativa humana de estabelecer determinadas prioridades para sua convivência harmoniosa com os robôs. É importante esclarecer, no entanto, que a convivência buscada pela sociedade construída por Asimov se traduz na procura da melhor forma de garantir a dedicação e a submissão dos robôs, sem ameaças à segurança humana e sem o desperdício dos valiosos investimentos realizados naquele desenvolvimento tecnológico.

Dessa forma, a ordem das leis da robótica foi estabelecida de acordo com a força de prioridade de cada diretriz, estando em primeiro lugar a garantia da segurança humana; em seguida, a obediência dos robôs ao homem; e, por último, o senso de autopreservação dos robôs. É interessante lembrar que a formulação dessas leis foi de grande importância para a discussão de questões éticas e morais envolvidas na criação de máquinas com inteligência artificial, sendo utilizadas como referência para o debate sobre os possíveis riscos do avanço tecnológico desordenado e as consequências das ações do homem no campo da ciência.

A ênfase na importância das leis para a existência dos robôs e para a sua relação com a humanidade, presente ao longo de toda a coleção, nos proporciona pistas para melhor compreender os conflitos criados por Asimov e abre espaço para a discussão da interpretação das leis, suas possíveis falhas e as consequências de alterações em seu conteúdo ou em sua ordem de prioridade. Esse aspecto se torna ainda mais interessante sob o ponto de vista da recepção dessas diretrizes como mensagens constituintes de um acervo lexical e da tentativa de reprodução do discurso tipicamente humano por máquinas de inteligência artificial.

Assim, ao propor leis destinadas a robôs, mas construídas sob a perspectiva da compreensão humana de vocabulário, contextualização, conceitos de ética, moral e lógica, o autor abre espaço para uma série de fascinantes conflitos. No conto Little lost robot, objeto deste estudo, o debate proposto por Asimov envolve uma modificação na primeira lei, situação que ocasiona uma reação inesperada de uma das máquinas criadas para servir em 
um projeto especial e sua crescente tentativa de resistência às demais leis, proporcionadas por sua reconfiguração cognitiva - que agora interpreta a existência das máquinas de maneira diferente.

A história trata do misterioso desaparecimento de um robô, que resulta na interrupção de todos os trabalhos desenvolvidos em um avançado centro de pesquisa militar localizado fora da Terra. 0 que deveria ser uma situação facilmente resolvida se transforma em uma ocorrência atípica e complicada em consequência de algumas atitudes tomadas previamente pelos militares e cientistas encarregados. Revela-se, então, que a base militar passara a utilizar alguns robôs diferenciados, com cérebros que não possuíam impressa em sua totalidade a primeira lei: "No robot may injure a human being, or, through inaction, allow a human being to come to harm" (AsImov 2004: 79).

A exploração da reorganização lexical da primeira lei e sua percepção pela competência comunicativa e capacidade cognitiva atribuída aos robôs, por meio de seus cérebros positrônicos, é uma rica premissa elaborada por Asimov. Partindo do alto desenvolvimento da inteligência artificial responsável pela existência de avançados robôs nas narrativas asimovianas, compreendemos que essas máquinas possuem uma grandiosa capacidade de acúmulo de informações, aspecto que seria responsável por torná-las hábeis a executar diferentes tarefas.

No entanto, a reprodução da aptidão cerebral humana, que nos habilita a realizar diversas ações sob as mais diferentes circunstâncias, foge ao alcance de um simples acúmulo de informações, pois se utiliza da capacidade cognitiva da estipulação de valores como a empatia, a criatividade, a moral, etc., que são relativos e específicos a diferentes situações, bem como da aquisição da competência comunicativa, que se deve à construção e à constante evolução da relação com a linguagem.

A limitação no desenvolvimento da capacidade de considerar todas as circunstâncias, consequências e resultados da tomada de decisões em níveis mais abstratos revela algumas das dificuldades propositalmente criadas por Asimov na aplicação das leis em situações que fogem do controle de suas personagens humanas. $\mathrm{O}$ autor parte dos conflitos relacionados à competência comunicativa e capacidade cognitiva de robôs e humanos para explorar 
questões como a ambiguidade e a dependência dos usos da linguagem em relação à cultura e aos comportamentos; a utilidade social de diferentes elementos ou indivíduos na sociedade; e os limites da tecnologia (MURPHY; Woods 2009: 14).

Partindo desse posicionamento, encontramos espaço para considerar que o conto Little lost robot não teria ficado de fora dessa tendência asimoviana, com a abordagem de aspectos da linguagem como a ambiguidade e a polissemia como mecanismos de construção para seu enredo.

\section{A polissemia em Little lost robot e as escolhas de tradução de $O$ pequeno robot perdido}

A utilização da polissemia, ou da ambiguidade em um contexto mais amplo, em obras literárias tem se mostrado uma interessante proposta criativa utilizada por renomados autores como James Joyce e Guimarães Rosa. Quando tratados como fonte de possibilidades criativas, esses fenômenos têm a capacidade de proporcionar uma multiplicidade de caminhos interpretativos a serem explorados tanto pelo autor em seu momento de composição, como pelos leitores já na recepção das obras.

Retomando o conceito de polissemia que decidimos adotar nesse estudo - como elemento natural e enriquecedor da linguagem, diretamente relacionado ao desenvolvimento da competência comunicativa e da capacidade cognitiva - podemos perceber seu papel na construção dos principais ganchos narrativos de Little lost robot.

O conto de Asimov apresenta dois importantes casos, o primeiro referente ao verbo modal may, utilizado no enunciado da primeira lei da robótica; e o segundo referente à expressão go lose yourself, instrução dada ao robô desaparecido. A multiplicidade de sentidos dos dois exemplos, aqui considerados de grande importância para a construção dos eventos narrados na 
história, adquire um caráter problemático quando precisa ser traduzida. Seria possível reproduzir a ambiguidade intencional de termos específicos ou a proposta geral que explora a ambiguidade como ferramenta criativa em uma outra língua?

A tradução do conto Little lost robot, publicada na coletânea Maravilhas da Ficção Científica (1958), revela algumas das dificuldades e soluções encontradas pelo tradutor quanto à transposição dessa diversidade de sentidos e ao trato de termos polissêmicos. Utilizando a discussão realizada sobre a tradução polissêmica, discutiremos as escolhas adotadas nessa versão e analisaremos se esses importantes elementos de constituição da obra puderam ser reproduzidos.

\subsection{Caso 1: a polissemia do verbo modal may}

O enredo de Little lost robot é construído sobre a premissa de uma alteração na primeira lei da robótica, que controla o comportamento dos robôs. Para entender melhor as consequências dessa modificação, é necessário analisarmos o enunciado dessa lei em sua forma original e a alteração proposta pelos cientistas e militares que desejavam dar continuidade aos trabalhos no centro de pesquisa.

Originalmente, a lei declara que "No robot may harm a human being, or through inaction, allow a human being to come to harm" (AsImov 2004: 79). A primeira parte da frase chama atenção por ser o ponto principal do enunciado, contendo a determinação inicial de que nenhum robô prejudique ou de alguma forma faça mal a um ser humano. Aqui, o termo may é o elemento principal da construção e por isso ganha especial atenção quanto a seu papel no valor semântico da frase.

May, assim como outros verbos modais da língua inglesa, frequentemente é compreendido como um termo não ambíguo, dependendo apenas da complementação de sentido fornecida pelo contexto de sua utilização. No entanto, uma análise mais profunda da origem do vocábulo e de suas diferentes 
aplicações mostra que esse termo pode ser relacionado à polissemia, sendo capaz de apresentar valores semânticos com diferentes impactos².

Para compreender melhor as possibilidades oferecidas por may, vejamos as definições do vocábulo encontradas no dicionário The Concise Oxford Dictionary of Current English (1982):

may ${ }^{1}$ v.aux (pres. may exc. 2 sing.) (arch.) mayst or may'est, neg. may not, (colloq.) mayn't; past might, neg. might not, (colloq.) mightn't pr. mī'tent; no other parts used). 1. Expr. Possibility (it may be true, opp. It cannot be true; you may (WELL ${ }^{3}$ ) walk ten miles without seeing one); he $\sim$ or might (= was perhaps) lose his way; afraid he might (would perhaps) lost it; we or might as well go (as not); that is as be, the truth of that is not yet determined; be that as it $\sim$, irrespective of the situation regarding that. 2 . Expr. permission you may go, opp. you may not or you must not go or cannot go; I wish I might); you might (= I request you to) call at the baker's. you etc. might (= you etc. ought to, yet do not) offer to help; you etc. might (= you etc. ought to) have offered; (iron.) who are you, may or might I ask?. 3. (In purpose - clauses, and after wish, fear, etc.) take, took such a course as may, might, avert the danger; I hope he may, hoped he might, succeed. 4. (Expr. wish) may you live to repent it!; may the best man win!; may it please your ladyship. 5. (In questions, emphasizing uncertainty) who may or might you be?. 6. Might-have-been, a past possibility, a person who might have been more eminent. [OE (1.sing.) mag, of preterit-past from; OS, OHG, GOTH. Mag, ON má, f. Gmc *mag- be strong f. IE *mogh-, *megh-; cf. MAIN², MIGHT'1 ]. may $^{2}$ n. (poet.) maiden. [ME, perh. f. ON maer, Goth. mawi f. Gmc. *maujo]]. May $^{3}$ n. 1. Fifth month of the year; (poet) bloom, prime; Queen of the $\sim$, girl chosen to be queen of games on MayDay. 2. (may) hawthorn (blossom). 3. II (Camb. Univ., in pl.) examinations held in May; boat races held during Week (late in May or early in June). 4. -apple, Amer. Herb bearing yellow eggshaped fruit in May; -bug, cockchafer; Day, 1 May esp. as festival with dancing, or as a international radio distress-signal [repr. pr. of $\mathrm{F}$ m'aider or help me]; II 'fair, opulent district in West End of London [named from fair formely held there in May]; 'flower any flower that blooms in May; may'fly, insect of order Ephemeroptera, living briefly in spring; may'pole, pole painted and decked with flowers and ribbons, for dancing round on May Day; queen, Queen of the May. [ME, f. OF mai f. L Maius (mensis month) of the goddess Maia] (SYKES 1982: 626-627).

Vemos que o termo may é citado em três entradas diferentes, classificadas de acordo com a relação entre os significados e a origem da palavra. A primeira definição, que nos serve de argumento para sua

\footnotetext{
${ }^{2}$ Alguns desses valores fazem referência à função epistêmica e deôntica do termo may. Nesse sentido, enquanto a abordagem epistêmica se preocupa com o que está relacionado à forma de aquisição do conhecimento e à crença humana, a lógica deôntica investiga os conceitos normativos aplicados à concepção da moral e da distinção entre o certo e o errado a partir de expressões com os termos "obrigação" e "dever" e suas derivações (GOMES 2008: 1). Assim, o termo may, quando interpretado pelo viés epistêmico, corresponde à proposta de probabilidade ou possibilidade, ligados à capacidade de acreditar no acontecimento de algo; enquanto uma visão deôntica do termo permite sua compreensão como referência à obrigação, permissão ou proibição.
}

TradTerm, São Paulo, v.35, junho/2020, p. 25-48

www.revistas.usp.br/tradterm 
classificação como item polissêmico, registra o termo como um condicionante de possibilidade, de permissão e uma indicação de desejo ou esperança, aplicações que derivam do mesmo étimo maeg. As demais entradas apresentam versões do termo como substantivo, função que não se aplica à análise aqui proposta.

No contexto da narrativa de Little lost robot e da declarada necessidade humana de controlar os robôs, a utilização de may proporciona uma natural interpretação da lei pela perspectiva da permissão, ou nesse caso específico, de sua negação. No entanto, podemos ver que a colocação do termo sob outros pontos de vista abre espaço para interpretações sutilmente diferentes, não reduzidas somente a um sentido de permissão ou proibição. Considerando as definições fornecidas pelo dicionário, a condição polissêmica e a discussão das seções anteriores quanto à intenção de Isaac Asimov em explorar a multiplicidade de sentidos e a competência comunicativa de humanos e robôs como artifício criativo na elaboração de suas histórias, levantamos a proposta de que o verbo modal may foi escolhido pelo autor especificamente por sua multiplicidade semântica.

Os objetivos dessa escolha seriam os de explorar, mais uma vez, a limitação cognitiva e comunicativa dos robôs diante das capacidades humanas, bem como as lacunas deixadas pela elaboração de ordens em um sistema linguístico que não é totalmente dominado pelo receptor e expandir a possibilidade de conflitos na relação entre o homem e a máquina.

As consequências da dualidade desse termo não seriam relevantes à primeira vista, considerando a análise da primeira lei em sua completude. No entanto, a partir do momento em que o enunciado é alterado para que o cumprimento das obrigações no centro militar de pesquisa seja possível, deparamo-nos com uma situação diferente. A lei, que agora se resume a "no robot may harm a human being" (AsIMOv 2004: 80) perde a especificidade de sua segunda metade, que a delimitava com mais critério, abrindo espaço para releituras referentes à não necessidade de interferência dos robôs quando um humano estiver em perigo; e à possível aplicação do verbo modal may no sentido de possibilidade ou capacidade. 
Analisemos, então, como foi realizada a tradução da lei na versão brasileira do conto de 1958. Contrariando a polissemia possivelmente proposta no termo original, a escolha de tradução feita em $O$ pequeno robot perdido (1958), descreve a primeira lei da seguinte maneira: "Nenhum robô fará mal a um ser humano, nem, pela sua inação, permitirá que advenha qualquer mal a um ser humano" (AsImov 1958: 203). A escolha do verbo fazer no futuro do presente do indicativo, comumente utilizado para tratar de uma ação ou acontecimento que muito provável ou definitivamente ocorrerá no futuro, indica a utilização de um discurso mais determinante que o original, que utilizou um elemento aberto à possibilidade. A construção original do enunciado com um termo que abarca tanto o sentido de permissão quanto o de possibilidade é perdida na definição de uma expressão monossêmica e determinante: nenhum robô fará mal.

Assim, podemos constatar que a opção do tradutor pela expressão de uma determinação proibitiva tende a reduzir o espaço de interpretação para que o robô construa sua nova lógica comportamental, elemento base para a justificativa das ações de insubordinação e atitude desafiadora adotada por ele.

É interessante refletir que esse sentido mais definitivo, adotado pela tradução de 1958, poderia ter sido facilmente alcançado na língua inglesa por meio da negação do verbo will, com a construção no robot will harm a human being, ou, inclusive, com o verbo shall, em no robot shall harm a human being, termo que possui um interessante peso cultural devido a sua utilização na bíblia. Entretanto, a escolha do autor pela palavra may parece explorar propositalmente a margem para mais de uma interpretação do enunciado.

Outro interessante apontamento é que esse caso específico, diferente da maioria dos casos polissêmicos diante da necessidade de tradução, oferece uma proposta de correspondência em português que se aproxima à proposta original da língua inglesa: o verbo poder, que também possui valores modais. Apesar de uma automática relação com o verbo modal da língua inglesa can, o termo poder em português também consegue abarcar os sentidos de permissão e possibilidade presentes em may. Dessa forma, teríamos em português: nenhum robô pode (ou poderá) fazer mal a um ser humano. 
A partir dos argumentos apresentados, confirmamos a percepção de que a leitura do texto traduzido não abrange as possibilidades de interpretação disponíveis no texto original, limitando-se a reproduzir o verbo modal may no português como um item lexical sem tanto impacto na construção da narrativa. A escolha pelo termo fará demonstra indicar, como justificativa à fuga do robô e ao seu novo comportamento desafiador, apenas a omissão da segunda parte da primeira lei da robótica, por ser essa uma motivação apresentada de maneira mais explícita na obra.

Suspeitamos, porém, que o motivo dessa escolha tradutória não tenha sido resultado da dificuldade em traduzir termos polissêmicos, mas da desconsideração ou da não identificação da existência de polissemia no termo, possibilidade antecipada por Delabastita (1993: 167). Um conceito que se aplica a esse cenário é o do "tradutor ingênuo", proposto por Stella Tagnin com base no conceito de "falante ingênuo" de Charles Fillmore (2005: 253). A autora estende a noção do falante ingênuo aos tradutores que não têm familiarização com as convencionalidades de uma língua, sendo incapazes de identificar suas ocorrências no texto original e, assim, perdendo-as em sua tradução.

Sobre as consequências da atuação do tradutor ingênuo, a autora comenta que a depender do caso elas podem passar despercebidas ou ter sérias consequências. Sob a perspectiva da riqueza polissêmica e da possível intenção de Asimov em explorar a competência comunicativa e a capacidade cognitiva de humanos e robôs, podemos considerar que o resultado da tradução brasileira de 1958 deixou de tratar de um interessante elemento de composição da obra, tendo como consequência a perda de um aspecto que traz singularidade à narrativa.

\subsection{Caso 2: sentidos literal e metafórico da expressão go lose yourself}

Além da polissemia do verbo modal may, outro elemento chama a atenção como artifício criativo baseado na relação entre a capacidade cognitiva dos robôs e a interpretação da linguagem humana. A expressão go lose yourself, 
dita pelo jovem físico Gerald Black ao robô que o auxiliava em seus experimentos - e caracterizada como causadora do desaparecimento do robô - é aplicada na narrativa como elemento figurativo que traz o coloquialismo do discurso humano. Indagado sobre como havia sido a última vez que vira o robô, Black, depois de alguma hesitação explica que, irritado com ele, havia-o mandado embora:

\footnotetext{
"(...) He was always annoying me on that subject and I was tired of it. I told him to go away-and that's all I saw of him."

"You told him to go away?" asked Dr. Calvin with sharp interest. "In just those words? Did you say 'Go away'? Try to remember the exact words."
}

There was apparently an internal struggle in progress. Black cradled his forehead in a broad palm for a moment, then tore it away and said defiantly, “I said, 'Go lose yourself.'” (ASIMOV 2004: 82)

A pergunta da Dra. Susan Calvin é fundamental neste ponto justamente porque as exatas palavras usadas por Black são a chave para entender por que o robô desapareceu. Recebendo uma ordem de literalmente "se perder", foi isso o que ele fez.

A frase é uma expressão informal comum na língua inglesa, que normalmente indica sentimentos como desprezo, irritação ou falta de paciência, externados pela sugestão de que o receptor da mensagem se retire do ambiente, da conversa, do assunto, etc. Outras aplicações da frase podem ser percebidas, por exemplo, em um contexto descontraído de brincadeira, confirmando a difícil abordagem da multiplicidade da expressão, que podemos caracterizar como uma oração de valor demasiadamente flexível, maneável por diversos fatores situacionais.

No entanto, mesmo em situações de brigas ou desentendimentos, é o caráter metafórico da expressão que possibilita sua utilização e não seu sentido literal. A exploração de uma oração com sentido metafórico como estopim para o acontecimento que gera todas as ações do conto reforça a hipótese de que o autor possui grande interesse na investigação de questões referentes à competência comunicativa. Tratando esse caso a partir da capacidade de 
compreensão do sentido aplicado pela frase dentro de um contexto específico, estamos adentrando, mais uma vez, o campo da cognição, a ser explorado do ponto de vista dos robôs.

Considerando que o caráter polissêmico da expressão demanda a identificação de um contexto para que possa ser interpretada por nós, possuidores de um vasto acervo lexical e cultural, podemos concluir que a limitação comunicativa e cognitiva dos robôs não permite que eles percebam tal informação como uma construção lexical que faz referência a outros significados que não os literais de cada palavra. Em outros termos, os robôs asimovianos, apesar de detentores de um extenso cabedal de informações das mais diversas áreas, não demonstram ser capazes de compreender metáforas. Como resultado das circunstâncias discutidas acima, ao ouvir a frase go lose yourself, dita pelo cientista que era seu superior imediato, o robô entendeu o enunciado como uma ordem literal e tratou exatamente de se perder, desaparecendo e empregando todos os esforços possíveis para não ser encontrado. Ele se comportou como um "falante ingênuo", que entre várias outras características indicadas por Fillmore, "não conhece as frases idiomáticas da língua" (FILlmore, apud TAGNIN 2005: 253). Considerando os relevantes fatores da utilização da expressão para a percepção de um robô de competência comunicativa e capacidade cognitiva limitada, vejamos agora como esse aspecto foi traduzido em $O$ pequeno robot perdido (1958).

- (...) Estava sempre me aborrecendo com êsse assunto, e eu já me sentia cansado daquilo. Disse-lhe que fôsse embora - e nunca mais o vi.

- $O$ senhor the disse que fôsse embora? - perguntou a Dra. Calvin, com agudo interêsse. - E que palavras, exatamente? Disse "Vá embora"? Tente lembrar-se das palavras exatas.

Houve, aparentemente, uma luta interior. Black balançou a testa na palma plana, por um momento, depois levantou-a e revelou, desafiadoramente:

- Eu disse: “Vá perder-se por aí!” (ASIMOV, 1958, p. 229)

TradTerm, São Paulo, v.35, junho/2020, p. 25-48

www.revistas.usp.br/tradterm 
A frase "vá perder-se por aí" (AsIMOV 1958: 229) usa do verbo reflexivo "perder-se" para produzir no texto em português uma amplitude semântica semelhante ao originário go lose yourself. Nesse exemplo, diferente do caso analisado anteriormente, o tradutor escolhe reproduzir a intenção polissêmica expressa nas palavras de Asimov - elemento central para o desenvolvimento da trama do pequeno robô -, mas o faz de modo que a frase escolhida acaba por gerar certo estranhamento por sua falta de proximidade com a linguagem do público leitor.

A aposta parece ter tido efeito positivo para a compreensão dos fatos que se seguem no conto, consequências da falta de capacidade do robô em entender o artifício polissêmico, mas não consegue reproduzir o mesmo impacto causado no texto original por não utilizar qualquer expressão idiomática comum da língua falada no Brasil.

A consideração do caráter metafórico da expressão original propõe que o conto traduzido reproduz o mais importante jogo de palavras elaborado pelo autor, ainda que a opção adotada resulte em certa falta de naturalidade, conferindo ao texto a imagem de uma produção literária distante da realidade brasileira.

Há de se reconhecer, no entanto, a dificuldade de encontrar um correspondente que supra todas as multiplicidades da oração original e que represente, simultaneamente, um equivalente comum na língua de destino de sua tradução. Por isso, é preciso considerar que o caminho tomado pelo tradutor em questão é uma das opções citadas por vários autores para a tradução polissêmica: a escolha de um sentido, ou uma proposta, baseado no contexto geral da obra.

Podemos relacionar a opção feita pela frase em português com o posicionamento defendido por Malone (1979: 209), que considera que todas as escolhas de traduções polissêmicas dependerão do conhecimento do tradutor sobre as intenções do autor. Entretanto, não é possível determinar se a escolha tradutória específica desse caso dependeu apenas do desejo de reproduzir o caráter polissêmico do texto original, ou se também foi influenciada pela dificuldade de encontrar uma expressão correspondente na língua de chegada. 
Ainda assim, temos que lembrar que mesmo que esteja a par de todos os casos de polissemia e ambiguidades em seu texto de trabalho e das consequências em tentar reproduzi-las, o tradutor sempre terá que fazer uma escolha, ainda que para isso encare as consequências da perda de nuances de sentido, jogos de palavras, trocadilhos, ou de naturalidade e contextualização com a língua de chegada. Dessa forma, antes de emitirmos algum juízo de valor sobre as escolhas aqui analisadas, consideramos interessante fornecer algumas informações acerca da publicação dessa coletânea no Brasil, cujas especificidades podem ajudar na compreensão de parte do caminho tomado por sua tradução e edição.

\subsection{O contexto de publicação de $O$ Pequeno Robot Perdido (1958) e suas possíveis contribuições às escolhas de tradução da obra}

Ao final da década de 1950, quando a coletânea Maravilhas da Ficção Científica foi publicada no Brasil, poucos registros da literatura de FC podiam ser encontrados no país. Como gênero de origem estrangeira, a FC já tinha fãs no Brasil, porém era muito restrita a publicações de pouco alcance como revistas e fanzines, um dos motivos pelos quais sua popularização junto ao público brasileiro demorou a se firmar. A antologia aqui apresentada é um dos exemplos do esforço empregado pelos entusiastas da literatura de FC para a divulgação do gênero no Brasil, iniciativa que, junto a outras parecidas, viria a apoiar a produção de uma Ficção Científica tipicamente brasileira.

Publicada pela editora Cultrix no ano de 1958, a coletânea reúne 15 contos do gênero de Ficção Científica ( $F C$ ), selecionados e organizados respectivamente por Wilma Pupo Nogueira Brito e Fernando Correia da Silva. A tradução dos textos é de autoria desconhecida, no entanto, pela prática comumente aplicada nas publicações de literatura específica nessa época, é possível que tenha sido realizada pelos próprios editores ou organizadores da coleção. 
A inserção da FC como literatura estrangeira traduzida no sistema literário vigente no Brasil entre as décadas de 1950 e 1960 não foi simples. Marcada pelo apreço de características como o nacionalismo e o regionalismo, a cultura literária do país se mantinha distante da objetividade científica e da exploração do desconhecido propostos pela FC. Assim, a tentativa de apresentação da FC aos leitores brasileiros pedia algumas medidas adaptativas que gerariam mudanças nos textos originais.

Consideramos que as escolhas adotadas nos casos de polissemia identificados em $O$ pequeno robot perdido podem indicar algumas dessas medidas, empregadas na tentativa de padronização de um texto de linguagem com características audaciosas a uma leitura fluida que não abrisse espaço para a dúvida de sentidos ou a confusão de significados. Outra possível contribuição do contexto da época à tradução do conto é o desconhecimento das possíveis intenções do autor, hoje extensamente descritas em estudos e entrevistas de fácil acesso. Esse aspecto é sustentado também a partir da compreensão de que outras obras do autor já haviam sido publicadas à época, mas que a reprodução dessas narrativas no Brasil ainda era de pouca circulação.

É difícil, entretanto, definir os exatos aspectos responsáveis pelo resultado apresentado na tradução em questão, já que é possível que seu perfil se deva a diversos aspectos, como: a não identificação do fenômeno polissêmico em alguns pontos da obra, opção considerada por autores como Delabastita (1993: 167) e Tagnin (2005: 253); a consideração do contexto principal da narrativa como principal justificativa para as escolhas tradutórias, ou a própria opção pessoal do tradutor - independente das circunstâncias nas quais o processo tenha sido realizado ou de seu encaixe na língua falada pelo públicoalvo - alternativa também já prevista por autores como Malone (1979: 208).

Independentemente das motivações que ocasionaram o resultado apresentado pelo texto traduzido, avaliamos que apesar de acarretar perdas significativas à riqueza semântica da obra e ao valor investigativo do texto sobre a capacidade cognitiva das máquinas em sua relação com a humanidade, as escolhas de tradução empregadas no conto traduzido de 1958 conseguiram ainda reproduzir a grande maioria dos eventos descritos na narrativa, 
contribuindo para o crescimento do número de obras de FC disponíveis ao público brasileiro da época.

\section{Considerações finais}

A investigação da hipótese de utilização da polissemia e da metáfora como artifício criativo na elaboração da narrativa Little lost robot (1947), de Isaac Asimov, se mostrou um exercício válido diante da discussão acerca do perfil do autor e de seu interesse em abordar a relação do homem com as máquinas - ou com a tecnologia em geral - em níveis mais profundos como o da competência comunicativa e o da cognição. Outro argumento que sustenta a proposta é a própria concepção da polissemia como fenômeno de multiplicidade semântica, enriquecimento da língua e exercício da capacidade comunicativa, percepção que se encaixa na investigação que o autor se propõe a realizar de elementos narrativos como a postulação das três leis da robótica por meio de suas interpretações, alterações ou reformulações sintáticas, capazes de gerar diversas situações e enredos a serem explorados.

Dessa forma, consideramos plausíveis as considerações tomadas a partir desse aspecto na caracterização dos dois casos de polissemia aqui apresentados, vistos como elementos relevantes à construção e ao enriquecimento da narrativa. O verbo modal may e a expressão go lose yourself se revelaram pontos chave para o desenvolvimento das ações descritas no conto, assim como para a justificativa da mudança de comportamento apresentada pelo robô desaparecido, auxiliadas pelo peso da modificação da primeira lei da robótica.

Quanto à tradução desses enunciados na primeira versão brasileira do conto, O pequeno robot perdido (1958), pudemos identificar tendências opostas do texto ao desconsiderar a multiplicidade de sentidos existentes na construção da narrativa asimoviana em um ponto e em tentar mantê-la em outro, em detrimento de uma familiaridade do público-alvo com o texto. A tradução atribuída ao termo may, em "no robot may harm a human being" (AsImov 2004: 
80), apresenta a escolha do verbo fazer conjugado no futuro do presente do indicativo, "nenhum robô fará mal a um ser humano" (Asımov 1958: 203), item lexical que não é capaz de representar a dualidade semântica disponível no texto original.

Em contrapartida, a interpretação conferida pela tradução da expressão "go lose yourself" pelo "vá perder-se por aí" (Asımov 1958: 208), demonstra uma consideração do caráter da frase como expressão metafórica, polissêmica, mas que perde sua singularidade e parte de seu valor como artifício criativo de linguagem ao afastar-se de expressões idiomáticas comuns à fala do público brasileiro - ao contrário do texto original, que utiliza uma frase popular do discurso informal na língua inglesa.

Para uma elaboração mais contextualizada de nossas percepções acerca das escolhas de tradução de $O$ pequeno robot perdido (1958), consideramos alguns fatores externos que podem ter influenciado na postura adotada na transposição do texto ao público brasileiro, como as circunstâncias de sua realização e publicação no país. As limitações editoriais, o pouco conhecimento das características de estilo do autor e os obstáculos ainda enfrentados pelo gênero literário de FC para se estabelecer no polissistema literário brasileiro podem ter sido alguns dos elementos que ocasionaram a adoção de um estilo menos audacioso, que se afastou de opções de tradução mais arriscadas.

Outra perspectiva que devemos considerar é de que as escolhas de tradução desse texto podem ter sido feitas unicamente devido à não identificação dos itens polissêmicos ou à adoção do sentido inicial perceptível pelo contexto dos casos na obra, independentemente dos elementos externos ao seu processo de tradução (como a intenção do autor ou o público-alvo). De qualquer maneira, consideramos que a tradução do conto foi capaz de reproduzir grande parte dos eventos descritos originalmente, contribuindo para a disponibilização de mais publicações de FC ao público brasileiro do final da década de 1950. 


\section{Referências}

AsImov, I. Fact Catches Up With Fiction. The New York Times. New York. November 19, 1961. Disponível em:

<http: / / www.nytimes.com/books/97/03/23/lifetimes/asi-v-

fact.html>. Acesso em: 08 mar. 2018.

AsImov, I. I, robot. New York: Spectra, 2004.

Bernardino, C. C. J. A polissemia da preposição alemã über: um estudo com base na Semântica Cognitiva. 2012. Dissertação (Mestrado em Língua e Literatura Alemã) - Faculdade de Filosofia, Letras e Ciências Humanas, Universidade de São Paulo, São Paulo, 2012. Disponível em: <http: / / www.teses.usp.br/teses/disponiveis/8/8144/tde-08012013123037>. Acesso em: 26 fev. 2018.

DelabastitA, D. There's a Double Tongue: An investigation into the translation of Shakespeare's wordplay, with special reference to Hamlet. Amsterdam: Rodopi, 1993.

Gomes, N. Um panorama da lógica deôntica. Kriterion, Belo Horizonte. v. 48, n. 117, 2008, p. 9-38. Disponível em:

$<$ https: / /www.scielo.br/scielo.php?pid=S0100-

512X2008000100002\&script=sci_arttext\&tlng=pt>. Acesso em: 08 mar. 2018.

SYKES, J. B. The Concise Oxford Dictionary of Current English. 7th ed., Gloucestershire: Clarendon Press, 1982.

MALONE, J. L. Source language polysemy and problems of translation. Babel, Paris, v. 25, n. 4, 1979, p. 207-209.

MURPHY, R.; WoODS, D. D. Beyond Asimov: the three laws of responsible robotics. IEEE Intelligent Systems, [online], v. 24, n. 4, 2009.

Oliveira, M. G. A. Dar: o verbo mais polissêmico da língua portuguesa. 1989. Dissertação (Mestrado em Letras) - Universidade Federal de Santa Catarina, Florianópolis, 1989. Disponível em: https://repositorio.ufsc.br/handle/123456789/75520. Acesso em: 26 fev. 2018.

RABAdÁn, R. Equivalencia y traducción. Problemática de la equivalencia, León: Universidad de León, 1991.

SILVA, F.; BRITO, W. (Org.). Maravilhas da Ficção Científica. São Paulo: Cultrix, 1958.

TAGNIN, S. E. O. O humor como quebra da convencionalidade. Revista brasileira de linguística aplicada 5.1, 2005. Disponível em: TradTerm, São Paulo, v.35, junho/2020, p. 25-48 
https://www.scielo.br/pdf/rbla/v5n1/13.pdf. Acesso em: 26 fev. 2005.

Ullmann, S. Semântica: uma introdução à ciência do significado. Trad. Mateus, J. A. O. Lisboa: Fundação Calouste Gulbekian. 1964.

VAERENBERGH, L. V. Polysemy and synonymy: Their management in Translation Studies dictionaries and in translator training. A case study. In: GAMBIER, Y.; DOORSLAER, L. V. (ed.). The Metalanguage of Translation. Amsterdam: John Benjamins Publishing Company, 2009.

Recebido em: 23/11/2018

Aceito em: 16/04/2020

Publicado em junho de 2020 